\title{
Cross section comparative study for comorbid migraine and major depression in epileptic patients: demographic, clinical, electroencahpalograhy and therapeutic implications
}

Hatem Anwar Elmassry ${ }^{1}$, Nahla Nagy ${ }^{2 *}$, Noha Samy ${ }^{3}$ and Maissa Eid ${ }^{3}$

* Correspondence:
nahlanagy64@yahoo.com
${ }^{2}$ Institute of Psychiatry, Ain Shams
University, 21 Ismail Ramzy Street,
Heliopolis, Cairo, Egypt
Full list of author information is
available at the end of the article

available at the end of the article

\begin{abstract}
Background: Overlapping relationships among migraine, epilepsy and major depression have been identified in both cross-sectional case-control and prospective studies. Clinical and neurophysiological examination of such comorbidity can illuminate shared pathophysiology, and can have profound implications for diagnosis, prognosis, and treatment.

Methods: During the period of January 2013 through July 2013, 87 cases were diagnosed as epilepsy in remission according to International League Against Epilepsy criteria. Migraine diagnosis was made according to the current International Classification of Headache Disorders-II. EEG and brain MRI were done to confirm the clinical diagnosis and physiological correlates.

Diagnosis of depression was based on detailed clinical and psychiatric assessment according to the DSM IV using SCID 1 and Hamilton depression scale for assessment of severity.

Results: A history of migraine was present in 19 (21.83\%), while major depression was present in $36(41.37 \%)$ of 87 epileptic patients. Comorbidity of migraine and major depression was significantly evident in younger age group $(p=0.000)$ and females $(p=0.01)$. Electroencephalography showed significantly more central and temporal epileptic discharge in patients with comorbid migraine and frontotemporal focal discharge in patients with major depression $(p=0.014)$.

Migraine onset was more likely to have occurred $1-3$ years after epilepsy was diagnosed in (36.84\%) of comorbid cases.

Conclusion: It is important to address comorbidity in treating patients with epilepsy. The diagnosis of atypical migraine symptoms can be quite difficult, in such cases EEG may be useful. Some antiepileptic drugs (AEDs) like divalproex sodium (valproate) and topiramate are effective in preventing migraine attacks, while others including phenytoin, oxcarbazepine, vigabatrin and clonazepam, are not effective in migraine prophylaxis. The antiepileptic drugs most closely associated with depression on initiation of treatment are vigabatrin, phenobarbitone, and topiramate.Further research on the nature and causes of the co-morbidity remains needed.
\end{abstract}

Keywords: Epilepsy, Migraine, Depression, Genetics, Antiepileptics, Antidepressants

\section{Biomed Central}




\section{Background}

The risk of migraine or depression is approximately twice in epilepsy compared to the general population (Le et al., 2011). This well established clinical finding suggests that the three disorders, epilepsy, migraine and depression might share many clinical features and underlying pathophysiological mechanisms.

The Adult Psychiatric Morbidity Survey 2007 interviewed 7,403 individuals living in England. Doctor-diagnosed epilepsy, asthma, diabetes, and migraine were ascertained by self-report, and extensive diagnostic and screening interviews. The estimated lifetime prevalence of epilepsy in adults was $1.2 \%$ (95\% confidence interval [CI] 1.0-1.5). Almost one-third of the people with epilepsy had an International Classification of Diseases, Tenth Revision (ICD-10) anxiety or depressive disorder (compared with one in six people without epilepsy). Among these, social phobia and agoraphobia, generalized anxiety disorder, depression, and measures of suicidality had strong associations with epilepsy. These associations were consistently stronger than those in people with asthma or diabetes, and similar to those in people reporting migraine or chronic headaches (Rai et al., 2012).

The complaint of headache may be confusing to the clinician. It may be part of prodromal symptoms of epilepsy or more commonly postictal. Using established diagnostic criteria may help to differentiate between comorbid migraine and epilepsy-related headaches in classical cases but this is not the case in atypical cases.

The concept of comorbidity could be examined on multiple levels.

First: patients could share the same genetic background as evident from family history and linkage studies. Significant evidence of linkage was found between a locus on 14q12-q23 and migraine suggestive of linkage in this region which was also found for epilepsy with generalized tonic-clonic seizures. In addition, significant evidence of linkage was found at a locus on 12q24.2-q24.3 for migraine alone and for the combined phenotype of migraine and epilepsy. These data suggest the occurrence of common susceptibility loci for epilepsy and migraine on chromosomes 14q12-q23 and 12q24.2-q24.3, implicating a shared genetic etiology for these two disorders (Polvi et al., 2012).

However, the presence of related genes is not enough by itself to explain comorbidity as many epigenetic factors can affect gene expression.

Second: across the life span, disease development may affect different neuronal circuits in different patients giving way to unique presentations in every patient in terms of disease prognosis and associated comorbidity. Migraine attacks could be epileptogenic and over time lead to the development of epilepsy, or, alternatively, recurrent seizures could lead to the development of migraine.

Depression and epilepsy may be linked temporally to seizures, but more commonly depression tends to occur inter-ictally. The bidirectional relationship between epilepsy and depression is not specific to Temporal Lobe Epilepsy (TLE) as indicated by failure to demonstrate alterations of serotonin binding properties in patients with epilepsy with or without symptoms of depression (Liik et al., 2013). There is strong evidence that the relationships among these comorbid disorders are bidirectional. Depression and suicidality are more prevalent among epilepsy patients, they have been shown to precede the onset of seizures and to occur 
more often than in controls following epilepsy onset (Winawer and Hesdorffer, 2010).

The idea that migraine may lead to epilepsy was once proposed as an explanation for the comorbidity (Le et al., 2011; Polvi et al., 2012). Epidemiological data indicate that this explanation is unlikely (Silberstein et al., 2008). If migraine caused epilepsy, for example by inducing brain injury, the incidence of epilepsy should be increased in individuals with preexisting migraine. The epidemiological results demonstrate that there is excess risk of epilepsy both before and after the onset of migraine, leading to the rejection of the unidirectional causality hypothesis. The simple genetic risk hypothesis was discarded and instead a theory was proposed that a state of brain hyperexcitability, which can be produced either by genetic factors or can be acquired (such as in a head injury), increases the risk of both migraine and epilepsy, thus leading to the comorbid association (Ottman \& Lipton 1996).

In each of the previous studies, one predictive factor for this comorbidity was examined and their results are still confusing with many study limitations including small sample size, diagnosis, comorbidity, and age of onset.

The bidirectional relationship and an evidence-based framework can guide the treatment of mood disorders that are comorbid with medical illness. Recent review on the links between mood disorders and common medical conditions, evaluated the efficacy and safety of pharmacologic and psychosocial treatments. The medical disorders most commonly encountered in adult populations with depression were cardiovascular disease, cerebrovascular disease, cancer, human immunodeficiency virus, hepatitis $C$ virus, migraine, multiple sclerosis, epilepsy, and osteoporosis. Emerging evidence suggests that depression comorbid with several medical disorders is treatable and failure to treat depression in medically ill patients may have a negative effect on medical outcomes (Ramasubbu et al., 2012).

Defining the comorbidity between epilepsy, migraine and depression is important to set suitable management plan avoiding some antiepileptics that can worsen other comorbidities and hence the patient's whole prognosis.

\section{Objectives}

The objectives of the current study were to examine the demographics (age of onset, sex), clinical (type of epilepsy) and neurophysiological (electroencephalographic changes) factors that help to predict the comorbidity of epilepsy, migraine and depression and therapeutic implications.

\section{Methods}

\section{Study setting}

This study is a cross sectional observational study conducted during the period of January 2013 through July 2013.

Epileptic patients were recruited from neurology out and inpatient departments from BenySweif and Ain Shams University hospitals after approval of the study protocol from the concerned ethical committee in both medical departments. This work has been carried out in accordance with code of ethics of the Word Medical Association 
and written informed consents were obtained from all subjects prior to participating in the study.

\section{Participants}

Of a total of 120 patients, as calculated by Graphpad Stat Mate, diagnosed as epileptics in remission according to International League Against Epilepsy (ILAE) criteria, 87 patients completed the study investigations, Electroencephalography (EEG) and Brain Magnetic Resonance Imaging (MRI). Fourty eight males and 39 females were included in the study. Their ages ranged from 18-45 years. Those with history of head trauma, drug abuse and serious medical or neuropsychiatric disorders were excluded.

All 87 subjects with epilepsy included in the study were assessed using semi structured neuropsychiatric interview done by neuropsychiatry specialist containing demographic data (age, sex, level of education, occupation, marital status, residence), past and family history of medical, psychiatric disorders and drugs, full history of epilepsy (onset, type, aura, frequency and drug response), associated migraine and depression (onset, number of previous episodes, presenting symptoms, suicidal thoughts or attempts, hospitalization and treatment). Antiepileptic drugs (AEDs) included carbamaezepine, lamotirgine, levitracetam and sodium valproate; Antimigraine drugs included triptans (Imigran) and ergot alkaloids (dihydroergotamine and methysergide), Gabapentin, pregabalin and selective serotonin reuptake inhibitors (SSRIs) were used for emotional disturbances (mainly ecitalopram and sertraline). Full medical and neuropsychiatric examination was done. Clinical diagnosis of migraine was obtained by neurological history and examination according to the current International Classification of Headache Disorders-II and diagnosis of depression according to the DSM IV using SCID 1 and Hamilton Depression Rating Scale (HDRS) for assessment of severity. All subjects were divided into 3 groups for comparing demographic, clinical and EEG variables, according to clinical and diagnostic criteria. Group 1was comprised of patients with epilepsy without comorbidity, group 2 included epileptic patients with comorbid migraine and group 3 epileptic patients with comorbid depression.

\section{Statistical analysis}

Collected data were analysed using statistical package of social sciences SPSS version 17. Qualitative variables were described in number and percentages. Quantitative variables were described in mean and standard deviations. Pearson Chi Square test was used to detect presence or absence of significant association between two categorical variables. Independent sample t-test was used to compare between means of different groups of patients. Analysis of Variance (ANOVA) tests were used when comparing quantitative data between more than two groups. $\mathrm{P}$ value was used to indicate the level of significance $(\mathrm{p}<0.05$ is considered significant, $\mathrm{p}<0.01$ is considered highly significant).

\section{Results}

Subjects who completed the study $(\mathrm{N}=87)$ diagnosed as epileptics in remission according to International League Against Epilepsy (ILAE) criteria, had an age 
range from $18-45$ and mean $+\mathrm{SD} 31.4+3.7$, Sex ratio $M / F=48 / 39$. Of the 87 included patients 47 (54.02\%) had generalized epileptic fits, while $24(27.58 \%)$ had temporal lobe fits and 16 (18.39\%) had extra-temporal focal fits. No evident changes were observed in Brain MRIs. The onset of epilepsy ranged from 12-18 years of age (as shown in Table 1).

Nineteen patients $(21.83 \%) 7$ males/12females met criteria of diagnosis of comorbid migraine, while 36 (41.37\%) met criteria of diagnosis of comorbid depression 11males/ 25 females with severity of HDRS ranging from 18-25 ( + SD $21+3.3)$. There were significant differences in gender between the three groups (epileptic patients without comorbidity, those with comorbid migraine, and those with comorbid depression), with comorbidity more likely to occur in females $(\mathrm{p}=0.01)$. In comparison between patients with and without comorbid migraine and depression, the comorbid group had significantly younger age of onset (Mean $+\mathrm{SD}=34+6.1$, $23+2.4,22+1.6$, respectively $(\mathrm{p}=0.000)$. Migraine was significantly encountered in epilepsy patients with epileptic discharge in the central and temporal regions and depression in frontotemporal epileptic changes $(\mathrm{p}=0.014)$ (as shown in Tables 2 and 3).

Three patients (15.7\%) described light flashes both as epileptic and migraine visual aura. Migraine onset followed epilepsy diagnosis in 12 patients (63.16\%), and in $7(36.84 \%)$ before epilepsy diagnosis, while depression was diagnosed $2-5$ years before epilepsy in 28 patients (77.7\%). This difference didn't reach statistical significance $(\mathrm{p}=0.63)$.

Table 1 Demographic and clinical characteristics of total epileptic patients subjects

\begin{tabular}{lll}
\hline & Number & Percentage \\
\hline Number & $\mathbf{8 7}$ & $\mathbf{1 0 0}$ \\
Age & $18-45$ & \\
Rexge & $32.1+3.5$ & \\
Male/Female & & $55.17 \% / 44.82 \%$ \\
Marital status & $48 / 39$ & \\
Single & 26 & $29.8 \%$ \\
married & 61 & $70.2 \%$ \\
Educational level & & \\
Illetrate & 8 & $9.19 \%$ \\
Primary level & 16 & $18.39 \%$ \\
Secondary technical level & 63 & $72.41 \%$ \\
Epilepsy type & & \\
Generalized epileptic fits & 47 & $\mathbf{5 4 . 0 2} \%$ \\
Temporal lobe fits & 24 & $\mathbf{2 7 . 5 8 \%}$ \\
Extratemporal focal fits & 16 & $\mathbf{1 8 . 3 9 \%}$ \\
Onset of epilepsy & Range & $21.83 \%$ \\
& $12-18$ years M + SD 13.2+ 1.1 & \\
\hline
\end{tabular}


Table 2 Demographic and clinical data for 3 groups of epileptic patients

\begin{tabular}{|c|c|c|c|c|}
\hline \multirow[t]{2}{*}{ Variable } & \multirow{2}{*}{$\begin{array}{l}\text { Group } 1 \\
\text { Epilepsy } \\
\text { without } \\
\text { comorbidity }\end{array}$} & \multirow{2}{*}{$\begin{array}{l}\text { Group } 2 \\
\text { Epilepsy with } \\
\text { comorbid migraine }\end{array}$} & \multirow{2}{*}{$\begin{array}{l}\text { Group } 3 \\
\text { Epilepsy with } \\
\text { comorbid depression }\end{array}$} & \multirow{2}{*}{$\begin{array}{l}\text { Significance } \\
P \text { value }\end{array}$} \\
\hline & & & & \\
\hline No (\%) & $32(36.78 \%)$ & $19(21.83 \%)$ & $36(41.37)$ & 0.004 \\
\hline Age range & Age Range & Age range & Age Range & 0.000 \\
\hline Mean + SD & $\begin{array}{l}21-42 \text { Mean + SD } \\
34+6.1\end{array}$ & $\begin{array}{l}\text { 18- } 32 \text { Mean + SD } \\
23+2.4\end{array}$ & $\begin{array}{l}20-28 \text { Mean + SD } \\
22+1.6\end{array}$ & \\
\hline SEX & SEX & SEX & SEX & 0.01 \\
\hline \multirow[t]{2}{*}{ Male :Female } & Male :Female & Male :Female & Male :Female & \\
\hline & $30: 2$ & $7: 12$ & $11: 25$ & \\
\hline \multirow{4}{*}{$\begin{array}{l}\text { Onset of } \\
\text { migraine }\end{array}$} & & after epilepsy diagnosis & after epilepsy diagnosis & 0.63 \\
\hline & & $12(63.16 \%)$ & 28(77.7\%) & \\
\hline & & before epilepsy diagnosis & before epilepsy diagnosis & \\
\hline & & $7(36.84 \%)$ & $8(22.22 \%)$ & \\
\hline \multirow{2}{*}{$\begin{array}{l}\text { Aura with } \\
\text { migraine }\end{array}$} & & +ve $3(15.7 \%)$ & & 0.361 \\
\hline & & -ve $16(84.3 \%)$ & & \\
\hline \multirow{3}{*}{$\begin{array}{l}\text { Severity of } \\
\text { depressive } \\
\text { symptoms }\end{array}$} & & & Range & \\
\hline & & & $18-25$ & \\
\hline & & & $\operatorname{HDRS}(21+3.3)$ & \\
\hline \multirow[t]{10}{*}{ Drug } & \multicolumn{2}{|c|}{ Antiepileptic drugs all patients $(\mathrm{N}=87)$} & & \\
\hline & \multicolumn{2}{|l|}{ Carbamaezepine 34} & & \\
\hline & \multicolumn{2}{|l|}{ lamotirgine 8} & & \\
\hline & \multicolumn{2}{|l|}{ levitracetam 9} & & \\
\hline & \multicolumn{2}{|l|}{ sodium valproate 50} & & \\
\hline & & Antimigraine drugs & selective serotonin reuptake & \\
\hline & & triptans (Imigran) 6 & $\begin{array}{l}\text { Innibitors (SSRIS) ecitalopram } \\
25 \text { sertraline } 11\end{array}$ & \\
\hline & & $\begin{array}{l}\text { ergot alkaloids } \\
\text { (dihydroergotamine } \\
\text { and methysergide) } 8\end{array}$ & & \\
\hline & & Gabapentin 12 & & \\
\hline & & Pregabalin 9 & & \\
\hline
\end{tabular}

There was significant difference among group in younger age of onset $(p=0.000)$ and female gender $(p=0.01)$ between patient groups with and without comorbid migraine and depression.

Table 3 Electroencephalographic changes in 3 groups of patients

\begin{tabular}{lllr}
\hline GROUP 1 & GROUP 2 & GROUP 3 & P value \\
\hline EEG Changes in epileptic & EEG Changes in epileptic & EEG changes in patients with & 0.014 \\
patients without comorbidity & patients with comorbid migraine & comorbid depression \\
N 32 (36.78\%) & N 19 (21.83\%) & N 36(41.37\%) \\
Focal discharge 11 & Focal discharge 15 & Focal discharge 29 \\
Frontal 4 & Frontal 3 & Frontal 11 \\
Central 4 & Central 7 & Central 3 \\
Temporal 3 & Temporal 5 & Temporal 15 \\
Paroxysmal discharge 21 & Paroxysmal discharge 6 & Paroxysmal discharge 9
\end{tabular}

Migraine was more common in epileptic patients with EEG discharge activity in central and temporal regions, while depression was more common with frontotemporal changes. 


\section{Discussion}

In this study, history of migraine was present in 19 patients (21.83 \%), while major depression was present in 36 patients (41.37\%) out of 87 patients diagnosed as epileptics in remission according to International League Against Epilepsy (ILAE) criteria. Comorbidity of migraine and major depression was significantly evident in younger age group $(\mathrm{p}=0.000)$ and females $(\mathrm{p}=0.01)$. Electroencephalography showed significantly more central and temporal epileptic discharge in patients with comorbid migraine and frontotemporal focal discharge in patients with major depression $(\mathrm{p}=0.014)$.

Migraine onset was more likely to have occurred 1-3 years after epilepsy was diagnosed in (36.84\%) of comorbid cases, while depression was diagnosed 2-5 year after epilepsy in $(77.7 \%)$ of depressed patients.

The prevalence of migraine in populations of individuals with epilepsy is estimated as $8-24 \%$ (Toldo et al., 2010), so that the risk of migraine is approximately twice that in the normal population (Ottman \& Lipton, 1994).

This coincides with our finding that $21.83 \%$ of our patients with epilepsy have comorbid migraine. The diagnosis of migraine in our study was significantly correlated with younger age and female gender. Thus comorbidity of migraine was more common in women which could be explained by hormonal effect (Le et al., 2011).

The onset of epilepsy proceeded the diagnosis of migraine 1-3 years in 12 patients (63.16\%). The same results were reported in other studies that found that migraine had more co-morbidities in females than males (Le et al., 2011).

Migraine attacks could be epileptogenic and over time lead to the development of epilepsy, or, alternatively, recurrent seizures could lead to the development of migraine. Across life span the disease development affects different neuronal circuits that are not the same in all patients giving way to unique presentation in every patient in terms of disease prognosis and associated comorbidity.

Estimates of the prevalence of depression in epilepsy vary. Epidemiological studies suggest A prevalence of $20-30 \%$ in those with recurrent seizures but only $6-9 \%$ in those whose epilepsy is in remission (Edeh \& Toone, 1987). These findings have been replicated by another community health survey (Tellez-Zenteno et al., 2007).

The above studies show that the prevalence rates of depression are much higher in epilepsy than those reported in the general population. In the present study major depression were encountered in 36 patients $(41.37 \%)$. Mean scores for HDRS $(21+3.3)$ ranged from moderate to severe cases particularly in patients who showed more frontotemporal epileptic changes.

Depressed mood, agitation, retardation, and absence of insight were the depressive symptoms more commonly seen among epilepsy patients as compared to those with migraine. People with temporal lobe epilepsy appear to be at greater risk than those with idiopathic generalized epilepsy, suggesting that it is not just the presence of seizures or social consequences of a diagnosis of epilepsy. Depression in a first degree relative has also been identified as an independent risk factor pointing to a genetic predisposition. Paradoxically, depression can follow remission of epilepsy either after epilepsy surgery or the initiation of an effective antiepileptic drug (Krishnamoorthy, 2004).

In the Epilepsy Family Study, among probands with epilepsy who were classified as having migraine on the basis of their self-reported symptoms, only $44 \%$ reported physician-diagnosed migraine. In the general population, $29 \%$ of men and $40 \%$ of 
women with migraine reported a medical diagnosis. Migraine onset was more likely to have occurred after epilepsy was diagnosed $(\mathrm{p}=0.0002)$, but was not more prevalent in those with intractable epilepsy (Silberstein \& Lipton, 2002).

This study shows that $56 \%$ of cases missed diagnosis by their doctors, either because they are not aware of the prevalence of comorbidity between epilepsy and migraine or they attributed the complain of headache to epilepsy.

In typical patients, the clinical history usually allows the separation of migraine and epilepsy. The diagnosis of atypical migraine symptoms can be quite difficult. However, a number of epileptic and nonepileptic syndromes may mimic migraine. In more complex cases, EEG and video-EEG monitoring are useful. Because migraine and epilepsy are associated, clinicians should be sensitive to the issue of concomitant diagnoses. Some patients with epilepsy and migraine may not report their headaches because the headaches are being effectively treated with an antiepileptic drug without a diagnosis of migraine. Because of its greater prevalence, migraine is common in people with epilepsy, whereas epilepsy is rare in migraineurs. The diagnosis and treatment of each disorder must take into account the potential presence of the other.

Cortical depolarization, is believed to underlie migraine. The initial event preceding onset of migraine is cellular hyperexcitability associated with localized epileptiform discharges. Glutamate is a critical mediator of the hyperexcitability in both focal seizures and migraine. Some antiepileptic drugs prevent the occurrence of migraine attacks, supporting the view that neuronal hyperexcitability is an initiating event. Strong support for a shared genetic basis comes from familial hemiplegic migraine (FHM), an autosomal dominant syndrome characterized by severe migraine, FHS arises as a result of mutations in genes for the membrane ion transport proteins CACNA1A (P/Q-type voltage-gated calcium channel), ATP1A2 $\left(\mathrm{Na}^{+}-\mathrm{K}^{+}\right.$ ATPase), and SCN1A (voltage-gated sodium channel). Allelic mutations in all three genes also cause generalized and in some cases focal epilepsy (Haan et al., 2008, Haut et al., 2006).

Migraine-like features sometimes characterize the headache that follows epileptic seizure (postictal headache, PIH). Forty percent of epileptic patients had PIH and 26\% of these patients had migraine-like PIH. Migraine-like PIH occurred significantly more often in temporal lobe epilepsies and occipital lobe epilepsies. The incidence of interictal migraine headache was significantly higher in patients with migraine-like PIH. These results suggest that migraine-like PIH is related to particular regions of epileptogenic focus and that susceptibility to migraine headache predisposes to migraine-like $\mathrm{PIH}$ (Ito et al., 2004).

Genetically determined dysfunction of ion channels seems to point to a common underlying mechanism for both paroxysmal disorders. It is likely that the development of specific drugs aimed at restoring ion-channel function and/or related cellular signalling pathways might benefit patients with epilepsy as well as those with migraine (Haan et al., 2008).

Current knowledge of the psychopharmacology of (AEDs) suggests that it is possible to distinguish between drugs with potential positive effects, and others with detrimental effects.

There is extensive evidence from randomized controlled clinical trials that the (AEDs) divalproex sodium (valproate) and topiramate are effective in preventing 
migraine attacks (Rogawski, 2008). The gabapentinoids gabapentin and pregabalin may also be effective in migraine therapy (D'Amico, 2010, Calandre et al., 2010). One other AED that has been reported to be useful in migraine prophylaxis is levetiracetam (Drake et al., 2001).

AEDs reduce neuronal hyperexcitability by various mechanisms (Macdonald \& Rogwski, 2008). Some AEDs, including phenytoin, oxcarbazepine, vigabatrin and clonazepam, are not effective in migraine prophylaxis. However, for both epilepsy and migraine, a proportion of patients are pharmacoresistant (around 30\% in both conditions) (Bermejo \& Dorado, 2009; Villani et al., 2011).

AEDs have a high psychotropic potential. In fact, this class of compounds is extensively used in psychiatric practice as mood stabilizers (Melvin et al., 2008), antianxiety agents (Vazquez \& Devinsky, 2003), or in withdrawal syndromes (Zullino et al., 2004) beyond their antiseizure effect, but possibly dealing with a sub-clinical hyperexcitability (Boutros et al., 2013).

The AEDs most associated with the occurrence of depressive symptoms in patients with epilepsy seem to be those which act at the benzodiazepine-GABA receptor complex, and include barbiturates, topiramate and vigabatrin (Mula et al., 2008).

Data on tiagabine, levetiracetam and felbamate seem to be associated with an intermediate risk and an incidence of inducing depression of about 3\% has been reported (Mulla and Shmitz, 2009).

The other AEDs show a low incidence of depression (less than 1\%). The antiepileptic drugs most closely associated with acute depression on initiation of treatment are vigabatrin, phenobarbitone, and topiramate. Depression with topiramate may be linked to abrupt cessation of seizures or drug toxicity (Mulla and Shmitz, 2009).

Evidence that antidepressants are associated with seizures comes largely from patients who have taken overdoses. That tricyclic overdose carries a high risk of provoked seizures is well documented, but the risk with low dose is probably minimal. Nevertheless, because of the risk of overdose in patients with depression tricyclic agents are best avoided and use of the selective serotonin reuptake inhibitors (SSRIs) or serotonin-norepinephrine reuptake inhibitors (SNRIs) are to be preferred (Krishnamoorthy, 2004).

Evidence to support this is hard to find, but there has been one open label study of sertraline in epilepsy that showed worsening of seizures in only $6 \%$ of patients. Given the morbidity and mortality associated with untreated depression, this risk is relatively low. Pharmacokinetic drug interactions between SSRIs and AED are rare, with the exception of inhibition of carbamazepine and phenytoin metabolism by fluvoxamine. Care needs to be taken with the combination of either carbamazepine or oxcarbazepine and SSRIs because of the tendency for both to cause hyponatraemia (Kanner et al., 2000).

\section{Study Limitations}

The most important limitation of this study is the small number of subjects studied and being cross sectional. It would be helpful in further research to conduct prospective follow up study on larger sample to predict comorbidity and prognosis overtime in relation to type of epilepsy, degree of improvement and type of drug used. 


\section{Conclusion}

Epilepsy, migraine and depression are comorbid conditions. This is likely due to shared genetic or environmental factors. In typical patients, the clinical history usually allows the separation of migraine and epilepsy. The diagnosis of atypical migraine symptoms can be quite difficult in such cases EEG may be useful. AEDs may have negative effects on mood and behaviour. Current knowledge on psychopharmacology of AEDs suggests that it is possible to distinguish between drugs with potential positive effects on mood, and others with detrimental effects.

\section{Competing interests}

The authors declare that they have no competing interests.

\section{Authors' contributions}

HE carried out the neurological examination of cases of epilepsy and migraine and reports of EEG, NN carried out psychiatric examination for cases of depression, Hamilton depression rating scale assessment and participated in the design of the study, NS performed the statistical analysis, ME participated in the sequence alignment and drafted the manuscript. All authors read and approved the final manuscript.

\section{Acknowledgements}

We acknowledge Dr. Nashaat Boutros for making substantial contributions to interpretation of data, was involved in drafting the manuscript and revising it critically for important intellectual content, Mrs Aida Merkees working in the neurophysiology unit for her help in doing the EEG study for all our patients and Prof. Mona ElSheikh for English language revision of the final draft.

We disclose no actual or potential conflict of interest including any financial, personal or other relationships with other people or organizations within three years of beginning the submitted work that could inappropriately influence, or be perceived to influence, this work. We received no funds to run this study from our institutions or any other sources I declare that the Submmitted article implies that the work described has not been published previously, that it is not under consideration for publication elsewhere, that its publication is approved by all authors and tacitly or explicitly by the responsible authorities where the work was carried out.

\section{Author details}

${ }^{1}$ Neurology department, Beny Sweif University, Cairo, Egypt. ${ }^{2}$ Institute of Psychiatry, Ain Shams University, 21 Ismail Ramzy Street, Heliopolis, Cairo, Egypt. ${ }^{3}$ Institute of Psychiatry, Ain Shams University, Cairo, Egypt.

Received: 17 January 2015 Accepted: 25 March 2015

Published online: 13 July 2015

References

Bermejo PE, Dorado R (2009) Zonisamide for migraine prophylaxis in patients refractory to topiramate. Clin Neuropharmacol 32:103-106

Boutros NN, Galloway MP, Ghosh S, Gjini K, Bowyer SM (2013) Abnormal Coherence Imaging in Panic Disorder: an MEG Investigation. NeuroReport 24(9):487-491

Calandre EP, Garcia-Leiva JM, Rico-Villademoros F, Vilchez JS, Rodriguez-Lopez CM (2010) Pregabalin in the treatment of chronic migraine: an open-label study. Clin Neuropharmacol 33:35-39

D'Amico D (2010) Pharmacological prophylaxis of chronic migraine: a review of double-blind placebo-controlled trials. Neurol Sci 31(Suppl 1):S23-S28

Drake ME, Greathouse NI, Armentbright AD, Renner JB (2001) Levetiracetam for preventative treatment of migraine. Cephalalgia 373:P2-113

Edeh J, Toone B (1987) Relationship between interictal psychopathology and type of epilepsy. Results of a survey in general practice. Br J Psychiatry 151:95-101

Haan J, Terwindt GM, van den Maagdenberg AMJM, Stam AH, Ferrari MD (2008) A Review of the Genetic Relation Between Migraine and Epilepsy. Cephalalgia 28:105-113

Haut SR, Bigal ME, Lipton RB (2006) Chronic disorders with episodic manifestations: focus on epilepsy and migraine. Lancet Neurol 5:148-157

Ito M, Adachi N, Nakamura F, Koyama T, Okamura T, Kato M, Kanemoto K, Nakano T, Matsuura M, Hara S (2004) Characteristics of Postictal Headache in Patients with Partial Epilepsy. Cephalalgia 24:23-28

Kanner A, Kozak A, Frey M (2000) The use of sertraline in patients with epilepsy: is it safe? Epilepsy and Behaviour 1:100-105

Krishnamoorthy E (2004) Treatment of psychiatric disorders in epilepsy. In: Shorvon S (ed) The treatment of epilepsy. Blackwell Science, Oxford, pp 255-261

Le H, Tfelt-Hansen P, Russell MB, Skytthe A, Kyvik KO, Olesen J (2011) Co-morbidity of migraine with somatic disease in a large population-based study. Cephalalgia 31:43-64

Liik M, Paris M, Vahter L, Gross-Paju K, Haldre S (2013) 123I-ADAM SPET imaging of serotonin transporter in patients with epilepsy and comorbid depression. Neurology 13:204

Macdonald RL, Rogwski MA (2008) Cellular effects of antiepileptic drugs. In: Engel J Jr, Pedley TA (eds) Epilepsy: a comprehensive textbook, 2nd edn. Kluwer/Lippincott Williams \& Wilkins, Wolters, pp 1433-1445 
Melvin CL, Carey TS, Goodman F, Oldham JM, Williams JW, Ranney LM Jr (2008) Effectiveness of antiepileptic drugs for the treatment of bipolar disorder: findings from a systematic review. J Psychiatr Pract 14(1):9-14

Mula M, Jauch R, Cavanna A, Collimedaglia L, Barbagli D, Gaus V, Kretz R, Viana M, Tota G, Israel H, Reuter U, Martus P, Cantello R, Monaco F, Schmitz B (2008) Clinical and psychopathological definition of the interictal dysphoric disorder of epilepsy. Epilepsia 49:650-656

Mulla M, Shmitz B (2009) Depression in Epilepsy: Mechanisms and Therapeutic Approach. Ther Adv Neurol Disord 2(5):337-344

Ottman R, Lipton RB (1994) Comorbidity of migraine and epilepsy. Neurology 44:2105-2110

Ottman R, Lipton RB (1996) Is the comorbidity of epilepsy and migraine due to a shared genetic susceptibility. Neurology 47:918-924

Polvi A, Siren A, Kallela M, Rantala H, Artto V, Sobel EM, Palotie A, Lehesjoki AE, Wessman M (2012) Shared loci for migraine and epilepsy on chromosomes 14q12-q23 and 12q24.2-q24.3. Neurology 78:202-209

Ra D, Kerr MP, McManus S, Jordanova V, Lewis G, Brugha TS (2012) Epilepsy and psychiatric comorbidity: a nationally representative population-based study. Epilepsia 53(6):1095-1103

Ramasubbu R, Taylor VH, Samaan Z, Sockalingham S, Li M, Patten S, Rodin G, Schaffer A, SBeaulieu S, Mclntyre RS, Canadian Network for Mood and Anxiety Treatments (CANMAT) Task Force (2012) The Canadian Network for Mood and Anxiety Treatments (CANMAT) task force recommendations for the management of patients with mood disorders and select comorbid medical conditions. Ann Clin Psychiatry 24(1):91-109

Rogawski MA (2008) Antiepileptic drugs and migraine. In: Olesen J, Ramadan N (eds) Innovative Drug Development for Headache Disorders (Frontiers in Headache Research Volume 16) Oxford University Press., pp 153-178

Silberstein SD, Lipton RB (2002) Headache and epilepsy. In: Ettinger AB, Devinsky O (eds) Managing epilepsy and co-existing disorders. Butterworth-Heinemann, Boston, pp 239-254

Silberstein SD, Lipton RB, Haut S (2008) Migraine. In: Engel J Jr, Pedley TA (eds) Epilepsy: a comprehensive Textbook. 2. Wolters Kluwer Health/Lippincott Williams \& Wilkins, Philadelphia, pp 2733-2743

Tellez-Zenteno JF, Patten SB, Jette N, Williams J, Wiebe S (2007) Psychiatric comorbidity in epilepsy: a population-based analysis. Epilepsia 48:2336-2344

Toldo I, Perissinotto E, Menegazzo F, Boniver C, Sartori S, Salviati L, Clementi M, Montagna P, Battistella PA (2010) Comorbidity between headache and epilepsy in a pediatric headache center. J Headache Pain 11:235-240

Vazquez B, Devinsky O (2003) Epilepsy and anxiety. Epilepsy and Behaviour 4:S20-\$25

Villani V, Ciuffoli A, Prosperini L, Sette G (2011) Zonisamide for migraine prophylaxis in topiramate-intolerant patients: an observational study. Headache 51:287-291

Winawer MR, Hesdorffer DC (2010) Migraine, epilepsy, and psychiatric comorbidity. Partners in crime. Neurology 74:1166-1168

Zullino DF, Khazaal Y, Hattenschwiler J, Borgeat F, Besson J (2004) Anticonvulsant drugs in the treatment of substance withdrawal. Drugs Today (Barc) 40:603-619

\section{Submit your next manuscript to BioMed Central and take full advantage of:}

- Convenient online submission

- Thorough peer review

- No space constraints or color figure charges

- Immediate publication on acceptance

- Inclusion in PubMed, CAS, Scopus and Google Scholar

- Research which is freely available for redistribution

Submit your manuscript at www.biomedcentral.com/submit 